\title{
Effect of PEEP on Dead Space in an Experimental Model of ARDS
}

\author{
Gerardo Tusman, Emiliano Gogniat, Matías Madorno, Pablo Otero, José Dianti, \\ Ignacio Fernandez Ceballos, Martín Ceballos, Natalí Verdier, Stephan H Böhm, \\ Pablo O Rodriguez, and Eduardo San Roman
}

\begin{abstract}
BACKGROUND: The difference between Bohr and Enghoff dead space are not well described in ARDS patients. We aimed to analyze the effect of PEEP on the Bohr and Enghoff dead spaces in a model of ARDS. METHODS: 10 pigs submitted to randomized PEEP steps of 0, 5, 10, 15, 20, 25 and $30 \mathrm{~cm} \mathrm{H}_{2} \mathrm{O}$ were evaluated with the use of lung ultrasound images, alveolar-arterial oxygen difference $\left(\mathbf{P}_{(\mathrm{A}-\mathrm{a}) \mathrm{O}_{2}}\right)$, transpulmonary mechanics, and volumetric capnography at each PEEP step. RESULTS: At PEEP $\geq 15 \mathrm{~cm} \mathrm{H}_{2} \mathrm{O}$, atelectasis and $P_{(\mathrm{A}-\mathrm{a}) \mathrm{O}_{2}}$ progressively decreased while endinspiratory transpulmonary pressure $\left(P_{L}\right)$, end-expiratory $P_{L}$, and driving $P_{L}$ increased (all $\left.P<.001\right)$. Bohr dead space $\left(\mathbf{V}_{\mathbf{D}_{\text {Bohr }}} / \mathbf{V}_{\mathbf{T}}\right)$, airway dead space $\left(\mathbf{V}_{\mathbf{D}_{\text {aw }}} / \mathbf{V}_{\mathbf{T}}\right)$, and alveolar dead space $\left(\mathbf{V}_{\mathbf{D}_{\text {alv }}} / \mathbf{V}_{\mathbf{T}_{\text {alv }}}\right)$ reached their highest values at PEEP $30 \mathrm{~cm} \mathrm{H}_{2} \mathrm{O}(0.69 \pm 0.10,0.53 \pm 0.13$ and $0.35 \pm 0.06$, respectively). At PEEP $<15 \mathrm{~cm} \mathrm{H}_{2} \mathrm{O}$, the increases in atelectasis and $\mathrm{P}_{(\mathrm{A}-\mathrm{a}) \mathrm{O}_{2}}$ were associated with negative end-expiratory $P_{L}$ and highest driving $P_{L} \cdot V_{D_{\text {Bohr }}} / V_{T}$ and $V_{D_{\text {aw }}} / V_{T}$ showed the lowest values at PEEP $0 \mathrm{~cm} \mathrm{H} \mathrm{H}_{2} \mathrm{O}\left(0.51 \pm 0.08\right.$ and $0.32 \pm 0.08$, respectively), whereas $\mathrm{V}_{\mathrm{D}_{\text {alv }}} / \mathrm{V}_{\mathrm{T}_{\text {alv }}}$ increased to $0.27 \pm 0.05$. Enghoff dead space and its derived $V_{D_{\text {alv }}} / V_{T_{\text {alv }}}$ showed high values at low PEEPs $(0.86 \pm 0.02$ and $0.79 \pm 0.04$, respectively) and at high PEEPs $(0.84 \pm 0.04$ and $0.65 \pm 0.12)$, with the lowest values at $15 \mathrm{~cm} \mathrm{H}_{2} \mathrm{O}(0.77 \pm 0.05$ and $0.61 \pm 0.11$, respectively; all $P<.001)$. CONCLUSIONS: Bohr dead space was associated with lung stress, whereas Enghoff dead space was partially affected by the shunt effect. Key words: dead space; PEEP; lung stress; ARDS; VILI; carbon dioxide. [Respir Care 2020;65(1):11-20. (C) 2020 Daedalus Enterprises]
\end{abstract}

\section{Introduction}

Volumetric capnography is a bedside tool to assess lung function and to adjust ventilatory settings in mechanically

\footnotetext{
Dr Tusman is affiliated with the Department of Anesthesiology, Hospital Privado de Comunidad, Mar del Plata, Argentina. Mr Gogniat and Drs Dianti, I.F. Ceballos, and San Roman are affiliated with the Department of Intensive Care Medicine, Hospital Italiano de Buenos Aires, Buenos Aires, Argentina. Dr Madorno is affiliated with Instituto Tecnológico Buenos Aires (ITBA), Buenos Aires, Argentina. Drs Otero, M Ceballos and Verdier are affiliated with the Anesthesia Department, Veterinary School, Universidad de Buenos Aires, Buenos Aires, Argentina. Dr Böhm is affiliated with the Department of Anesthesiology and Intensive Care Medicine, Rostock University Medical Center, Rostock, Germany. Dr Rodriguez is affiliated with Pulmonary and Critical Care Medicine, Instituto universitario CEMIC (Centro de Educación Médica e Investigaciones Clínicas), Buenos Aires, Argentina.
}

Dr Tusman has disclosed a relationship with Maquet. Dr Madorno is partner and manager of MBMed. The other authors have disclosed no conflicts of interest. ventilated patients. ${ }^{1-3}$ Using expired $\mathrm{CO}_{2}$ as a tracer, volumetric capnography estimates dead space $\left(\mathrm{V}_{\mathrm{D}}\right)$ based on the mass balance equation originally described by Bohr. ${ }^{4}$ In the clinical field, $\mathrm{V}_{\mathrm{D}}$ is commonly estimated applying the Enghoff modification of Bohr's original formula, replacing the alveolar $\mathrm{P}_{\mathrm{CO}_{2}}$ value with the arterial value $\left(\mathrm{P}_{\mathrm{aCO}_{2}}\right)^{5,6}$ This approach, however, contaminates the true dead space in which alveoli are ventilated but not perfused by the effect of shunting blood through non-ventilated lung areas. Because this $\mathrm{P}_{\mathrm{aCO}}$-based apparent dead space does not represents any real volume, it is also called fictitious dead space. ${ }^{7}$ Today, true dead space according to Bohr's formula can be estimated because modern volu-

\footnotetext{
Correspondence: Gerardo Tusman MD, Department of Anesthesiology, Hospital Privado de Comunidad, Mar del Plata, Argentina. E-mail: gtusman@hotmail.com.
}

DOI: $10.4187 /$ respcare. 06843 
metric capnography can measure mean alveolar $\mathrm{P}_{\mathrm{CO}_{2}}$ in a noninvasive way. ${ }^{8}$ Therefore, Bohr dead space $\left(\mathrm{V}_{\mathrm{D}_{\text {Bohr }}}\right)$ and its subcomponents of airway dead space $\left(\mathrm{V}_{\mathrm{D}_{\mathrm{aw}}}\right)$ and alveolar dead space $\left(\mathrm{V}_{\mathrm{D}_{\text {alv }}}\right)$ have become available at the bedside on a breath-by-breath basis. ${ }^{8,9}$

\section{See the Related Editorial on Page 129}

It is accepted that positive-pressure ventilation increases $\mathrm{V}_{\mathrm{D}_{\mathrm{aw}}}$ and $\mathrm{V}_{\mathrm{D}_{\text {alv }}}$ by dilating the conducting airways and by decreasing pulmonary capillary perfusion at the alveolarcapillary membrane, respectively. ${ }^{10,11}$ These effects depend mainly on the ventilatory settings and on how the pressures and volumes delivered by the ventilator are distributed within the lungs. ${ }^{12,13}$ We hypothesized that the Bohr dead space is a surrogate for lung stress, which is one of the major determinants of ventilator-induced lung injury, because it is derived exclusively from gas sampled from all parts of the lungs. ${ }^{14}$ The Enghoff index, however, does not reflect lung stress very well in the presence of a high shunt.

The objective of this study was to test the effect of PEEP on the parameters of Bohr and Enghoff in an animal model of ARDS under constant ventilation and stable hemodynamic conditions.

\section{Methods}

This study was performed at the laboratory of the Department of Anesthesiology, Veterinary School, Universidad de Buenos Aires, Buenos Aires, Argentina, with the corresponding approval of the Institutional Animal Ethical Committee (CICUAL Register number 08/14).

\section{Baseline Ventilation and ARDS Model}

Ten Landrace pigs age 3-4 months weighing $29 \pm 10 \mathrm{~kg}$ were included in the study. All of the animals were placed in the supine position and anesthetized using standard techniques. Lungs were ventilated through a cuffed 7.5 endotracheal tube with a Puritan Bennett 980 (Puritan Bennett, Carlsbad, California) in VC-CMV mode using a tidal volume $\left(\mathrm{V}_{\mathrm{T}}\right)$ of $10 \mathrm{~mL} / \mathrm{kg}$, a breathing frequency of 24 breaths $/ \mathrm{min}$ at an inspiratory-expiratory ratio of 1:2, PEEP $10 \mathrm{~cm} \mathrm{H}_{2} \mathrm{O}$, and $\mathrm{F}_{\mathrm{IO}_{2}}$ 1.0.

We used a 2-hit experimental ARDS model. Repeated lung lavages with normal saline $\left(30 \mathrm{~mL} / \mathrm{kg}\right.$ at $\left.37^{\circ} \mathrm{C}\right)$ were performed until $\mathrm{P}_{\mathrm{aO}_{2}} / \mathrm{F}_{\mathrm{IO}_{2}} \leq 200 \mathrm{~mm} \mathrm{Hg}$ at PEEP $10 \mathrm{~cm} \mathrm{H_{2 }}$ O. The animals were then submitted to $120 \mathrm{~min}$ of injurious mechanical ventilation at PEEP $0 \mathrm{~cm} \mathrm{H}_{2} \mathrm{O}, \mathrm{V}_{\mathrm{T}}$ $15 \mathrm{~mL} / \mathrm{kg}$, frequency 12 breaths/min, an inspiratory-expiratory ratio of $1: 2$, and $\mathrm{F}_{\mathrm{IO}_{2}}$ 1.0. Thereafter, baseline ventilatory settings were restored; the success of the model

\section{QUICK LOOK}

\section{Current knowledge}

It is accepted that positive-pressure ventilation with PEEP increases Bohr dead space by dilating the conducting airways and decreasing pulmonary capillary perfusion at the alveolar level. Thus, dead space is considered a surrogate of lung stress despite lack of clear evidence.

\section{What this paper contributes to our knowledge}

In an animal model of ARDS with ventilation at constant settings, high levels of PEEP (ie, $>15 \mathrm{~cm} \mathrm{H}_{2} \mathrm{O}$ ) increased airway and alveolar dead space, whereas PEEP $<15 \mathrm{~cm} \mathrm{H}_{2} \mathrm{O}$ increased only the alveolar component of dead space. These findings were related to high inspiratory lung stress, plateau pressure, driving pressure, and lung elastance.

was confirmed with a $\mathrm{P}_{\mathrm{aO}_{2}} / \mathrm{F}_{\mathrm{IO}_{2}} \leq 200 \mathrm{~mm} \mathrm{Hg}$, and lung ultrasound imaging showing bilateral atelectasis in the dependent lungs. ${ }^{15}$

\section{Gas Exchange, Lung Ultrasound, and Hemodynamics}

Arterial blood samples were analyzed with the Enterprise Point-of-Care System (Epocal, Ottawa, Ontario, Canada), and the oxygen alveolar-to-arterial partial pressure difference was calculated as follows:

$$
\mathrm{P}_{(\mathrm{A}-\mathrm{a}) \mathrm{O}_{2}}=\left[\mathrm{P}_{\mathrm{iO}_{2}}-\left(\mathrm{P}_{\mathrm{aCO}_{2}} / 0.8\right)\right]-\mathrm{P}_{\mathrm{aO}_{2}}
$$

where $\mathrm{P}_{(\mathrm{A}-\mathrm{a}) \mathrm{O}_{2}}$ is the alveolar-arterial oxygen difference and $\mathrm{P}_{\mathrm{iO}_{2}}$ is the inspired oxygen pressure.

Lung ultrasound assessed atelectasis with the use of the Micromaxx echograph (Sonosite, Bothell, Washington). A linear probe $(8-12 \mathrm{MHz})$ was used to examine the chest after dividing it into 4 quadrants, 2 ventral and 2 dorsal, with the mid-axillary line and the diaphragm as limits. Normally aerated lung was defined as the presence of lung sliding and A lines, whereas atelectasis was defined as the presence of condensation on air bronchograms. ${ }^{15}$ The presence of atelectasis was determined in each quadrant for each animal during all protocol steps.

Mean arterial pressure, stroke volume variation, and cardiac index were measured with the Vigileo hemodynamics monitor (Edwards Lifesciences, Irvine, California). Saline solution was infused in line with the protocol at a baseline rate of $4 \mathrm{~mL} / \mathrm{kg} / \mathrm{h}$. Between PEEP steps, a combination of $5 \mathrm{~mL} / \mathrm{kg}$ boluses of saline and intravenous infusion of norepinephrine (initial dose 0.01 
$\mu \mathrm{kg} / \mathrm{min}$ ) were administered if mean arterial pressure $<60 \mathrm{~mm} \mathrm{Hg}$, stroke volume variation $>12 \%$, and/or cardiac index $\leq 2.5 \mathrm{~L} / \mathrm{min} / \mathrm{m}^{2}$.

\section{Respiratory Mechanics}

Respiratory mechanics were measured with the Fluxmed monitor (MBMed, Buenos Aires, Argentina) after calibration of the flow and pressure sensors. Data were recorded on a laptop using the corresponding software FluxReview (MBMed). At each PEEP level, intrinsic PEEP and plateau pressure $\left(\mathrm{P}_{\text {plat }}\right)$ were measured with end-expiratory and end-inspiratory holds, respectively, each lasting $>3$ s. Respiratory driving pressure was determined as $\mathrm{P}_{\text {plat }}$ - total PEEP. Compliance of the respiratory system $\left(\mathrm{C}_{\mathrm{RS}}=\mathrm{V}_{\mathrm{T}} /\right.$ driving pressure $)$ and airway resistance $\left(\mathrm{R}_{\mathrm{aw}}=\right.$ peak- $\mathrm{P}_{\text {plat }}$ pressure/inspiratory flow $)$ were calculated.

An esophageal latex balloon $7 \mathrm{~cm}$ long was placed at mid-esophageal position and inflated with $1 \mathrm{~mL}$ air. Its position was checked with the occlusion method described for mechanically ventilated patients. ${ }^{16}$ Transpulmonary pressure $\left(\mathrm{P}_{\mathrm{L}}\right)$ was calculated as the difference between airway and esophageal $\left(\mathrm{P}_{\mathrm{es}}\right)$ pressures. End-inspiratory $\mathrm{P}_{\mathrm{L}}$ and end-expiratory $\mathrm{P}_{\mathrm{L}}$ were the transpulmonary pressures measured at the end of the inspiratory and expiratory pauses, respectively. Driving $\mathrm{P}_{\mathrm{L}}$ was computed as end-inspiratory $\mathrm{P}_{\mathrm{L}}$ - end-expiratory $\mathrm{P}_{\mathrm{L}}$. Total elastance of the respiratory system (ie, driving pressure/ $\mathrm{V}_{\mathrm{T}}$ ) was divided into lung elastance (ie, driving $\mathrm{P}_{\mathrm{L}} / \mathrm{V}_{\mathrm{T}}$ ) and chest wall elastance (ie, inspiratory-expiratory $\mathrm{P}_{\mathrm{es}} / \mathrm{V}_{\mathrm{T}}$ ).

\section{Volumetric Capnography}

Dead space was measured with the NICO monitor (Philips, Wallingford, Connecticut) using a mainstream Capnostat sensor placed at the airway opening between the $\mathrm{Y}$ piece and the endotracheal tube. Data were recorded with a laptop, and volumetric capnograms were analyzed off-line as previously described (see supplemental materials at http://www.rcjournal.com). ${ }^{8,9,17-19}$ Figure 1 depicts volumetric capnography and the related Bohr and Enghoff formulas.

\section{Protocol}

The protocol started recording baseline ventilation as describe above. PEEP values of $0,5,10,15,20,25$ and $30 \mathrm{~cm} \mathrm{H}_{2} \mathrm{O}$ at constant ventilation were randomly assigned by sealed envelopes and applied for 10 min each. ${ }^{20}$ After each PEEP step, the ventilator circuit was disconnected for $15 \mathrm{~s}$, followed by baseline ventilation for $10 \mathrm{~min}$. Lung ultrasound confirmed the presence of atelectasis before any PEEP step to maintain similar baseline conditions and
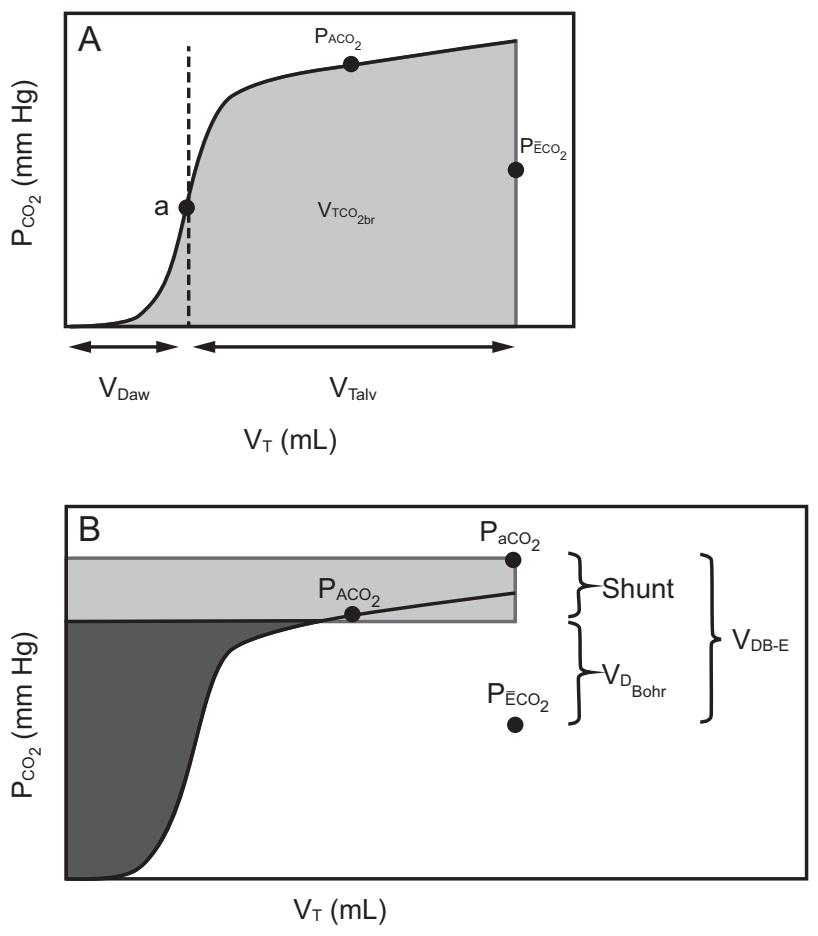

$\left.\begin{array}{l}\text { Shunt }=\frac{\mathrm{P}_{\mathrm{aCO}_{2}}-\mathrm{P}_{\mathrm{ACO}}}{\mathrm{P}_{\mathrm{aCO}}} \\ \mathrm{V}_{\mathrm{B}_{\mathrm{Bohr}}}=\frac{\mathrm{P}_{\mathrm{ACO}}-\mathrm{P}_{\overline{\mathrm{ECO}}}}{\mathrm{P}_{\mathrm{ACO}}}\end{array}\right\} \mathrm{V}_{\mathrm{DB}-\mathrm{E}}=\frac{\mathrm{P}_{\mathrm{aCO}}-\mathrm{P}_{\overline{\mathrm{ECO}}}}{\mathrm{P}_{\mathrm{aCO}}}$

Fig. 1. Volumetric capnography-derived parameters and dead space measurements. (A) Conceptual depiction of volumetric capnography: Fowler technique separates the tidal volume $\left(V_{T}\right)$ in an airway dead space $\left(\mathrm{V}_{\mathrm{D}_{\mathrm{aw}}}\right)$ from the alveolar tidal volume $\left(\mathrm{V}_{\mathrm{T}_{\mathrm{alv}}}\right)$ at the curve's inflection point $a$. (B) Bohr dead space $\left(\mathrm{V}_{\mathrm{D}_{\text {Bohr }}}\right)$ is represented by the black area; the gray area represents the virtual, fictitious, or apparent dead space created by the shunt effect when using the Enghoff modification of the Bohr formula. (C) Formulas representing the respective approaches by Bohr and Enghoff. $\mathrm{V}_{\mathrm{T}_{\mathrm{CO}_{2}}}=$ the amount of $\mathrm{CO}_{2}$ eliminated in one tidal breath; $\mathrm{P}_{\mathrm{ACO}_{2}}=$ alveolar $\mathrm{P}_{\mathrm{CO}_{2}} ; \mathrm{P}_{\mathrm{E}_{\mathrm{CO}_{2}}}=$ mixed expired partial pressure of $\mathrm{CO}_{2}$.

additional lung lavages were performed if lung aeration improved.

Volumetric capnography and respiratory mechanics were recorded continuously, and the last 2 min of each PEEP step was analyzed. Arterial blood gas samples and lung ultrasound images were performed toward the end of each PEEP step.

\section{Statistical Analysis}

Statistical analysis was performed with R 3.3.3 (R Foundation for Statistical Computing, Vienna, Austria). First, 
Table 1. Gas Exchange and Hemodynamics Variables During the Protocol

\begin{tabular}{|c|c|c|c|c|c|c|c|c|c|}
\hline \multirow{2}{*}{ Parameter } & \multirow{2}{*}{ Baseline } & \multicolumn{7}{|c|}{ PEEP } & \multirow{2}{*}{$P$} \\
\hline & & $0 \mathrm{~cm} \mathrm{H}_{2} \mathrm{O}$ & $5 \mathrm{~cm} \mathrm{H}_{2} \mathrm{O}$ & $10 \mathrm{~cm} \mathrm{H}_{2} \mathrm{O}$ & $15 \mathrm{~cm} \mathrm{H}_{2} \mathrm{O}$ & $20 \mathrm{~cm} \mathrm{H}_{2} \mathrm{O}$ & $25 \mathrm{~cm} \mathrm{H}_{2} \mathrm{O}$ & $30 \mathrm{~cm} \mathrm{H}_{2} \mathrm{O}$ & \\
\hline \multicolumn{10}{|l|}{ Gas exchange } \\
\hline $\mathrm{pH}$ & $7.20 \pm 0.06$ & $7.16 \pm 0.06$ & $7.16 \pm 0.08$ & $7.20 \pm 0.06$ & $7.21 \pm 0.07$ & $7.20 \pm 0.08$ & $7.23 \pm 0.09$ & $7.20 \pm 0.06$ & $<.001$ \\
\hline $\mathrm{P}_{\mathrm{aO}_{2}}, \mathrm{~mm} \mathrm{Hg}$ & $126 \pm 70$ & $51 \pm 22$ & $55 \pm 20$ & $106 \pm 59$ & $216 \pm 124$ & $332 \pm 169$ & $549 \pm 141$ & $571 \pm 56$ & $<.001$ \\
\hline $\mathrm{P}_{(\mathrm{A}-\mathrm{a}) \mathrm{O}_{2}}, \mathrm{~mm} \mathrm{Hg}$ & $510 \pm 66$ & $571 \pm 30$ & $570 \pm 28$ & $526 \pm 61$ & $421 \pm 125$ & $305 \pm 166$ & $97 \pm 129$ & $68 \pm 50$ & $<.001$ \\
\hline $\mathrm{P}_{\mathrm{aCO}_{2}}, \mathrm{~mm} \mathrm{Hg}$ & $62 \pm 14$ & $73 \pm 15$ & $71 \pm 12$ & $65 \pm 14$ & $61 \pm 11$ & $61 \pm 13$ & $58 \pm 16$ & $59 \pm 14$ & $<.001$ \\
\hline $\mathrm{P}_{(\mathrm{A}-\mathrm{a}) \mathrm{CO}_{2}}, \mathrm{~mm} \mathrm{Hg}$ & $30 \pm 8$ & $51 \pm 13$ & $46 \pm 11$ & $37 \pm 11$ & $30 \pm 10$ & $29 \pm 8$ & $25 \pm 5$ & $25 \pm 4$ & $<.001$ \\
\hline \multicolumn{10}{|l|}{ Hemodynamics } \\
\hline Heart rate, beats/min & $122 \pm 32$ & $114 \pm 26$ & $121 \pm 32$ & $120 \pm 30$ & $116 \pm 34$ & $123 \pm 35$ & $128 \pm 35$ & $122 \pm 36$ & .83 \\
\hline Mean arterial pressure, $\mathrm{mm} \mathrm{Hg}$ & $93 \pm 14$ & $94 \pm 30$ & $96 \pm 29$ & $95 \pm 18$ & $94 \pm 18$ & $91 \pm 14$ & $81 \pm 17$ & $79 \pm 14$ & .058 \\
\hline Cardiac index, $\mathrm{L} / \mathrm{min} / \mathrm{m}^{2}$ & $3.1 \pm 1.1$ & $4.8 \pm 1.1$ & $3.7 \pm 1.1$ & $4.2 \pm 0.3$ & $3.6 \pm 0.9$ & $3.4 \pm 1.3$ & $3.8 \pm 1.5$ & $3.0 \pm 1.1$ & .11 \\
\hline Stroke volume variation, \% & $8 \pm 2$ & $7 \pm 3$ & $7 \pm 2$ & $7 \pm 1$ & $9 \pm 4$ & $15 \pm 6$ & $19 \pm 10$ & $30 \pm 14$ & $<.001$ \\
\hline \multicolumn{10}{|c|}{$\begin{array}{l}\text { Data are presented as mean } \pm \mathrm{SD} \text {. Analysis of variance } P \text { values testing the influence of PEEP in each parameter are included in the last column. } \\
\mathrm{P}_{(\mathrm{A}-\mathrm{a}) \mathrm{O}_{2}}=\text { alveolar-arterial oxygen difference } \\
\mathrm{P}^{-}\end{array}$} \\
\hline
\end{tabular}

mean values of each variable at each PEEP step for all animals were calculated. Then, to overrule pseudo-replication due to repeated measurement of the same animal, relationships between gas exchange and mechanics were assessed using mixed-effect regression models. The animal was included as a random intercept. A similar approach was used when fitting repeated measurement analysis of variance models (using the respective PEEP step as an independent variable). Model marginal (related to fixed factors) and conditional coefficients of determination for mixed-effect linear regression models were calculated using MuMIn package. ${ }^{21}$ To explore potential non-linear relationships between variables, second-degree polynomial (quadratic) regression models were used. Continuous variables are expressed as mean $\pm \mathrm{SD}$, and $P$ value $\leq .05$ was considered statistically significant.

\section{Results}

All animals were successfully studied without major hemodynamic events or barotrauma.

\section{Gas Exchange, Lung Ultrasound, and Hemodynamics}

Data recorded at baseline ventilatory settings and stable hemodynamics confirmed the impairment of gas exchange caused by the model (Table 1). Arterial hypoxemia was present in most animals at $\mathrm{PEEP} \leq 5 \mathrm{~cm} \mathrm{H} \mathrm{H}_{2} \mathrm{O}$, and $\mathrm{P}_{\mathrm{aO}_{2}}$ increased progressively with PEEP from $51 \pm 22 \mathrm{~mm} \mathrm{Hg}$ at PEEP 0 to $571 \pm 56 \mathrm{~mm} \mathrm{Hg}$ at PEEP $30 \mathrm{~cm} \mathrm{H}_{2} \mathrm{O}$ (Table $1, P<.001)$. $\mathrm{P}_{(\mathrm{A}-\mathrm{a}) \mathrm{O}_{2}}$ was directly related to the number of atelectatic quadrants per animal (marginal $\left.\mathrm{R}^{2}=0.789, P<.001\right)$. Figure 2 depicts a high $\mathrm{P}_{(\mathrm{A}-\mathrm{a}) \mathrm{O}_{2}}$ in the presence of atelectasis at low PEEP and how this index decreased by the alveolar recruitment observed at high levels of PEEP.

As shown in Table 1 , the highest $\mathrm{P}_{\mathrm{aCO}_{2}}$ and $\mathrm{P}_{(\mathrm{A}-\mathrm{a}) \mathrm{CO}_{2}}$ values were noted at constant ventilation using low PEEP values (both $P<.001)$. We found that highest $\mathrm{P}_{\left(\mathrm{a}-\mathrm{ACO}_{2}\right)}$ was associated with the presence of atelectasis and highest $\mathrm{P}_{\left(\mathrm{A}-\mathrm{aO}_{2}\right)}$ (marginal $\mathrm{R}^{2}=0.37, P<.001$; and marginal $\mathrm{R}^{2}=0.45, P<.001$, respectively). At $\mathrm{PEEP} \leq 15 \mathrm{~cm} \mathrm{H}_{2} \mathrm{O}$, hypercapnia was related more to the presence of atelectasis and shunt effect than to the increase in dead space at PEEP $\geq 15 \mathrm{~cm} \mathrm{H}_{2} \mathrm{O}$ (Fig. 2). Hemodynamic parameters showed no significant difference between the PEEP steps, and only stroke volume variation increased significantly at PEEP $>20 \mathrm{~cm} \mathrm{H}_{2} \mathrm{O}$ (Table 1).

\section{Lung Mechanics}

Changes in PEEP affected lung mechanics without any effect on chest wall elastance $(P=.23)$. Total elastance of the respiratory system changed by the difference in lung elastance every time PEEP changed (Table 2, $P<.001$ ). At constant tidal volume, $\mathrm{C}_{\mathrm{RS}}$ and $\mathrm{R}_{\mathrm{aw}}$ changed at the different PEEP steps (Table $2, P<.001$ ). The highest $\mathrm{C}_{\mathrm{RS}}$ value of $15.8 \pm 5.0 \mathrm{~mL} / \mathrm{cm} \mathrm{H}_{2} \mathrm{O}$ was found at a mean PEEP of $15 \mathrm{~cm} \mathrm{H}_{2} \mathrm{O}$, and the lowest $\mathrm{R}_{\mathrm{aw}}$ value of $19.9 \pm 7.3 \mathrm{~cm} \mathrm{H} \mathrm{H}_{2} \mathrm{O} / \mathrm{L} / \mathrm{s}$ was observed at PEEP $30 \mathrm{~cm} \mathrm{H}_{2} \mathrm{O}$.

Figure 2 shows that $\mathrm{P}_{\text {plat }}$ remained quite similar at PEEP values $\leq 15 \mathrm{~cm} \mathrm{H}_{2} \mathrm{O}$ but then increased progressively with PEEP, reaching the highest value at PEEP $30 \mathrm{~cm} \mathrm{H}_{2} \mathrm{O}\left(57.6 \pm 8.3 \mathrm{~cm} \mathrm{H}_{2} \mathrm{O}\right)$. The lowest endinspiratory $\mathrm{P}_{\mathrm{L}}$ of $17.9 \pm 3.9 \mathrm{~cm} \mathrm{H}_{2} \mathrm{O}$ was found at PEEP 10, but this increased at higher PEEP values $(P<.001)$. End-expiratory $\mathrm{P}_{\mathrm{L}}$ presented increases proportional to the PEEP applied, showing negative val- 


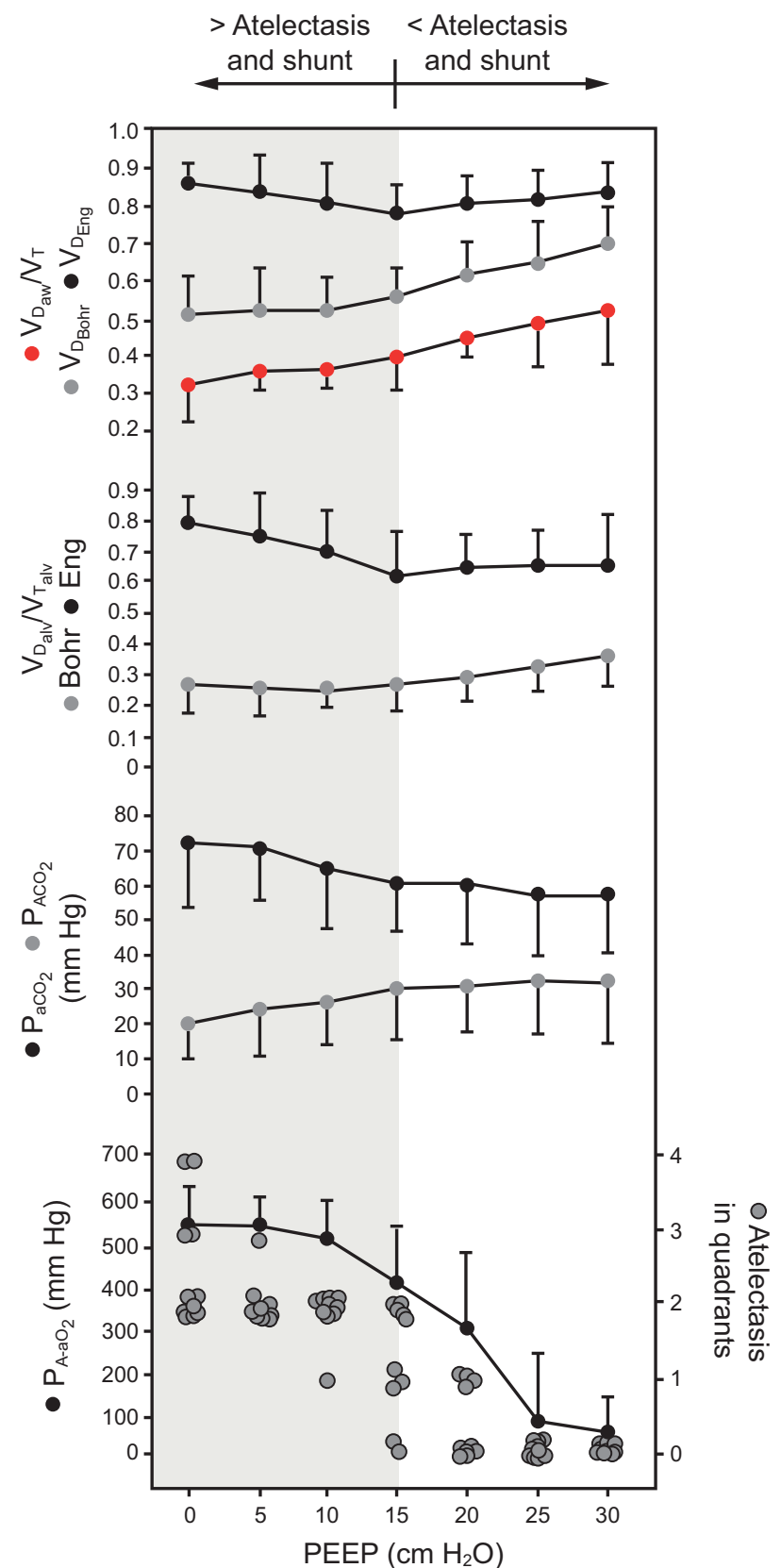

Fig. 2. Gas exchange and performance of the Bohr and Enghoff parameters as a function of PEEP, which was used as a surrogate of shunt. Atelectasis was diagnosed with lung ultrasound. Cumulative presence of atelectasis of all quadrants (ventral and dorsal, right and left) of all animals is presented as circles for each level of PEEP. A circle at zero means that the animal did not develop atelectasis. Analysis of variance was used for all variables $(P<.001)$. $\mathrm{V}_{\mathrm{D}_{\text {Bohr }}}$ and $\mathrm{V}_{\mathrm{D}_{\text {Eng }}}=$ physiological dead space using the Bohr and Enghoff formulas, respectively; $V_{D_{a w}} V_{T}=$ airway dead space; $\mathrm{V}_{\mathrm{D}_{\text {alv }}} \mathrm{V}_{\mathrm{T}_{\mathrm{Tlv}}}=$ ratio of alveolar dead space to alveolar tidal volume; $\mathrm{P}_{\mathrm{ACO}_{2}}=$ alveolar $\mathrm{P}_{\mathrm{CO}_{2}} \cdot \mathrm{P}_{(\mathrm{A}-\mathrm{a}) \mathrm{O}_{2}}=$ alveolar-arterial $\mathrm{O}_{2}$ difference.

ues at PEEP $\leq 10 \mathrm{~cm} \mathrm{H}_{2} \mathrm{O}$ and positive values in all pigs as soon as PEEP values were $\geq 20 \mathrm{~cm} \mathrm{H}_{2} \mathrm{O}$ $(P<.001)$.
Both driving pressure and driving $\mathrm{P}_{\mathrm{L}}$ showed a nonlinear behavior with PEEP, reaching their lowest values at PEEP $15\left(19.6 \pm 4.8 \quad \mathrm{~cm} \mathrm{H}_{2} \mathrm{O}\right)$ and PEEP 20 $\left(15.5 \pm 4.8 \mathrm{~cm} \mathrm{H}_{2} \mathrm{O}\right)$, respectively. These parameters, however, increased at both ends of the PEEP scale, reaching highest values at $\mathrm{PEEP} 0$, with a driving pressure of $31.1 \pm 6.6 \mathrm{~cm} \mathrm{H}_{2} \mathrm{O}$ and a driving $\mathrm{P}_{\mathrm{L}}$ of $27.4 \pm 6.7 \mathrm{~cm} \mathrm{H}_{2} \mathrm{O}$ (Fig. 3).

\section{Volumetric Capnography}

Dead space estimated with the Bohr equation showed significant changes with PEEP (Table 3 , all $P<.001$ ). Whereas $\mathrm{V}_{\mathrm{D}_{\text {Bohr }}} / \mathrm{V}_{\mathrm{T}}$ and $\mathrm{V}_{\mathrm{D}_{\text {aw }}} / \mathrm{V}_{\mathrm{T}}$ increased progressively with PEEP, the alveolar component showed the lowest value of $0.25 \pm 0.02$ at PEEP $10 \mathrm{~cm} \mathrm{H}_{2} \mathrm{O}$ but increased again at low and high PEEP values (Fig. 2).

$\mathrm{V}_{\mathrm{D}_{\text {Eng }}} / \mathrm{V}_{\mathrm{T}}$ and its derived $\mathrm{V}_{\mathrm{D}_{\text {alv }}} / \mathrm{V}_{\mathrm{T}_{\text {alv }}}$, on the other hand, presented high values at low and high PEEP values, showing their lowest value at PEEP $15 \mathrm{~cm} \mathrm{H}_{2} \mathrm{O}(0.77 \pm 0.05$ and $0.61 \pm 0.11$, respectively). Figure 2 indicates that the highest $\mathrm{V}_{\mathrm{D}_{\mathrm{Eng}}} / \mathrm{V}_{\mathrm{T}}$ and $\mathrm{V}_{\mathrm{D}_{\text {alv }}} / \mathrm{V}_{\mathrm{T}_{\text {alv }}}$ values were more associated with the atelectasis-related shunt than with the overdistention caused by high PEEP values.

Figure 4 shows a quadratic model of dead space as a function of end-exppiratory and end-inspiratory $\mathrm{P}_{\mathrm{L}}$. The Bohr dead space value and its airway subcomponent showed a nonlinear increase with end-expiratory $\mathrm{P}_{\mathrm{L}}$ (marginal $\mathrm{R}^{2}=0.53$ and $\mathrm{R}^{2}=0.54$, respectively, $P<.001$ ), whereas end-inspiratory $\mathrm{P}_{\mathrm{L}}$ induced a linear increase because the squared terms were not statistically significant in either case (marginal $\mathrm{R}^{2}=0.29$ and $\mathrm{R}^{2}=0.24$, respectively, $P<.001)$. The relationship between $\mathrm{V}_{\mathrm{D}_{\text {alv }}} / \mathrm{V}_{\mathrm{T}_{\mathrm{alv}}}$ and endexpiratory $\mathrm{P}_{\mathrm{L}}$ fitted a U-shaped function when the Bohr method was used (marginal $\mathrm{R}^{2}=0.26, P<.001$ ). The quadratic function established by the model revealed minimum $\mathrm{V}_{\mathrm{D}_{\text {alv }}} / \mathrm{V}_{\mathrm{T}_{\text {alv }}}$ at end-expiratory $\mathrm{P}_{\mathrm{L}}$ of $-1.43 \mathrm{~cm} \mathrm{H} \mathrm{H}_{2} \mathrm{O}$. However, according to the quadratic model, $\mathrm{V}_{\mathrm{D}_{\text {alv }}} / \mathrm{V}_{\mathrm{T}_{\text {alv }}}$ showed a linear relationship with end-inspiratory $\mathrm{P}_{\mathrm{L}}$ (marginal $\mathrm{R}^{2}=0.24, P<.001$; quadratic term Wald test, $P=.42)$.

$\mathrm{V}_{\mathrm{D}_{\mathrm{Eng}} / \mathrm{V}_{\mathrm{T}}}$ responded differently to PEEP than $\mathrm{V}_{\mathrm{D}_{\text {Bohr }}} / \mathrm{V}_{\mathrm{T}}$ (Fig. 4). $\mathrm{V}_{\mathrm{D}_{\mathrm{Eng}}} / \mathrm{V}_{\mathrm{T}}$ decreased as with end-expiratory $\mathrm{P}_{\mathrm{L}}$ (marginal $\mathrm{R}^{2}=0.12, P=.038$ ) and was unrelated to end-inspiratory $\mathrm{P}_{\mathrm{L}}$ (marginal $\mathrm{R}^{2}=0.05, P=.25$ ). The derived $\mathrm{V}_{\mathrm{D}_{\text {alv }}} / \mathrm{V}_{\mathrm{T}_{\text {alv }}}$ showed a straight line as a function of end-expiratory $\mathrm{P}_{\mathrm{L}}$ (marginal $\mathrm{R}^{2}=0.36, P<.001$ ), and it was also unrelated to end-inspiratory $\mathrm{P}_{\mathrm{L}}$ (marginal $\mathrm{R}^{2}=0.04, P=.29$ ).

\section{Discussion}

The main findings of this study can be summarized as follows. First, the Bohr dead space and transpulmonary 
Table 2. Respiratory Mechanics

\begin{tabular}{|c|c|c|c|c|c|c|c|c|c|}
\hline \multirow{2}{*}{ Parameter } & \multirow{2}{*}{ Baseline } & \multicolumn{7}{|c|}{ PEEP } & \multirow{2}{*}{$P$} \\
\hline & & $0 \mathrm{~cm} \mathrm{H}_{2} \mathrm{O}$ & $5 \mathrm{~cm} \mathrm{H}_{2} \mathrm{O}$ & $10 \mathrm{~cm} \mathrm{H}_{2} \mathrm{O}$ & $15 \mathrm{~cm} \mathrm{H}_{2} \mathrm{O}$ & $20 \mathrm{~cm} \mathrm{H}_{2} \mathrm{O}$ & $25 \mathrm{~cm} \mathrm{H}_{2} \mathrm{O}$ & $30 \mathrm{~cm} \mathrm{H}_{2} \mathrm{O}$ & \\
\hline Tidal volume, $\mathrm{mL}$ & $295 \pm 84$ & $303 \pm 83$ & $293 \pm 86$ & $299 \pm 83$ & $300 \pm 83$ & $298 \pm 84$ & $301 \pm 83$ & $297 \pm 91$ & .12 \\
\hline $\mathrm{P}_{\text {plat }}, \mathrm{cm} \mathrm{H}_{2} \mathrm{O}$ & $31.4 \pm 5.9$ & $33.3 \pm 5.9$ & $34.0 \pm 5.6$ & $33.6 \pm 4.3$ & $35.5 \pm 5.1$ & $40.5 \pm 4.7$ & $48.1 \pm 7.2$ & $57.6 \pm 8.3$ & $<.001$ \\
\hline Total PEEP, $\mathrm{cm} \mathrm{H}_{2} \mathrm{O}$ & $10.2 \pm 0.9$ & $2.3 \pm 2.1$ & $6.1 \pm 1.0$ & $10.7 \pm 1.2$ & $15.9 \pm 0.9$ & $20.8 \pm 0.7$ & $25.8 \pm 0.7$ & $30.6 \pm 0.9$ & $<.001$ \\
\hline $\mathrm{C}_{\mathrm{RS}}, \mathrm{mL} / \mathrm{cm} \mathrm{H}_{2} \mathrm{O}$ & $14.5 \pm 5.5$ & $9.9 \pm 2.9$ & $10.7 \pm 3.6$ & $13.4 \pm 4.0$ & $15.8 \pm 5.0$ & $15.8 \pm 5.3$ & $14.7 \pm 6.3$ & $12.2 \pm 6.7$ & $<.001$ \\
\hline $\mathrm{R}_{\mathrm{aw}}, \mathrm{cm} \mathrm{H} \mathrm{H}_{2} \mathrm{O} / \mathrm{L} / \mathrm{s}$ & $27.1 \pm 11.1$ & $38.2 \pm 7.9$ & $35.5 \pm 5.9$ & $25.4 \pm 6.4$ & $23.8 \pm 4.9$ & $22.1 \pm 5.4$ & $22.1 \pm 4.6$ & $19.9 \pm 7.3$ & $<.001$ \\
\hline $\mathrm{E}_{\mathrm{CW}}, \mathrm{cm} \mathrm{H} \mathrm{H}_{2} \mathrm{O} / \mathrm{dL}$ & $1.2 \pm 0.7$ & $1.5 \pm 0.5$ & $1.7 \pm 0.5$ & $1.3 \pm 0.5$ & $1.3 \pm 0.5$ & $1.4 \pm 0.9$ & $1.6 \pm 1.0$ & $1.8 \pm 1.1$ & .23 \\
\hline $\mathrm{E}_{\mathrm{L}}, \mathrm{cm} \mathrm{H} \mathrm{H}_{2} \mathrm{O} / \mathrm{dL}$ & $5.9 \pm 1.7$ & $8.9 \pm 2.8$ & $7.9 \pm 2.5$ & $6.2 \pm 1.7$ & $5.2 \pm 1.6$ & $5.1 \pm 1.7$ & $5.4 \pm 1.7$ & $6.9 \pm 2.4$ & $<.001$ \\
\hline $\mathrm{E}_{\mathrm{tot}}, \mathrm{cm} \mathrm{H} \mathrm{H}_{2} \mathrm{O} / \mathrm{dL}$ & $7.2 \pm 2.2$ & $10.5 \pm 2.9$ & $9.7 \pm 2.9$ & $7.6 \pm 2.0$ & $6.5 \pm 1.9$ & $6.5 \pm 1.9$ & $6.9 \pm 2.1$ & $8.7 \pm 2.9$ & $<.001$ \\
\hline
\end{tabular}

Data are presented as mean $\pm \mathrm{SD}$. Analysis of variance $P$ values testing the influence of PEEP in each parameter are included in the last column.

$\mathrm{P}_{\text {plat }}=$ plateau pressure

$\mathrm{C}_{\mathrm{RS}}=$ compliance of the respiratory system

$\mathrm{R}_{\mathrm{aw}}=$ airway resistance

$\mathrm{E}_{\mathrm{CW}}=$ chest wall elastance

$\mathrm{E}_{\mathrm{L}}=$ lung elastance

$\mathrm{E}_{\mathrm{tot}}=$ total elastance
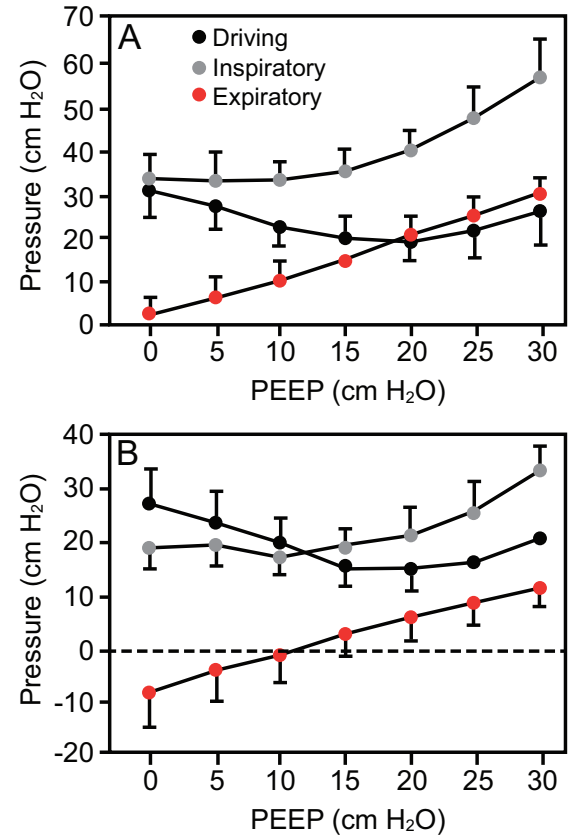

Fig. 3. Airway (A) and transpulmonary (B) pressures during the study. Driving, end-inspiratory, and end-expiratory pressures were obtained from the pressure signals obtained at the airway opening and from esophageal pressure measurements with the esophageal balloon. Analysis of variance was used for all variables $(P<.001)$.

lung mechanics changed with PEEP. Second, $\mathrm{V}_{\mathrm{D}_{\mathrm{aw}}} / \mathrm{V}_{\mathrm{T}}$ increased almost linearly with PEEP $\geq 15 \mathrm{~cm} \mathrm{H}_{2} \mathrm{O}$. Third, the Enghoff modification of the original Bohr formula leads to significant effects from shunt on the estimated results, but it is unable to discern between the effects of shunt and high inspiratory lung stress on its derived alveolar dead space value. Fourth, in this model, hypercapnia was more related to atelectasis-induced shunt effects at low PEEP values than to the dead space created by high PEEP values. Fifth, at PEEP values $\geq 15 \mathrm{~cm} \mathrm{H}_{2} \mathrm{O}$, high $\mathrm{P}_{\text {plat }}$ and end-inspiratory $\mathrm{P}_{\mathrm{L}}$ values clearly suggest lung overdistention and were related to decreases in expired $\mathrm{CO}_{2}$ per breath and increases in both the Bohr and the Enghoff dead spaces. Finally, at PEEP values $<15 \mathrm{~cm} \mathrm{H}_{2} \mathrm{O}$, $\mathrm{P}_{\text {plat }}$ and end-inspiratory $\mathrm{P}_{\mathrm{L}}$ remained constant but above the recommended safe values, while driving pressure, driving $\mathrm{P}_{\mathrm{L}}$, and lung elastance increased. The increase in driving pressures at low PEEP values was associated with decreases in the amount of $\mathrm{CO}_{2}$ eliminated per breath $\left(\mathrm{V}_{\mathrm{T}} \mathrm{CO}_{2}\right)$ and increases in $\mathrm{V}_{\mathrm{D}_{\text {alv }}} / \mathrm{V}_{\mathrm{T}_{\text {alv }}}$.

The effect of PEEP on airway dead space has been described before. ${ }^{1,9,10,22} \quad \mathrm{~V}_{\mathrm{D}_{\text {aw }}}$ is calculated according to Fowler and is independent of the Bohr and Enghoff equations. ${ }^{9}$ Fowler postulated that the midpoint of phase 2 of capnograms represents the mean interface or limit between gas transport by diffusion within alveoli and by convection within the conducting airways. ${ }^{19}$ Such interface is dynamic, moving closer to the respiratory bronchiole at end-inspiration. It constitutes the limit between airway and alveoli, ${ }^{9,23,24}$ thereby enabling the distinction between those parts of the tidal volume belonging to the conducting airways from those belonging to the alveolar compartment on a volumetric capnogram..$^{1-3}$

Positive-pressure ventilation increases $\mathrm{V}_{\mathrm{D}_{\mathrm{aw}}} / \mathrm{V}_{\mathrm{T}}$ by 2 potential mechanisms: one is related to the dilation of the airways by increased airway pressures and pre-inspiratory lung volumes based on its intrinsic elastic nature ${ }^{25}$; the other mechanism is related to the end-inspiratory displacement of the interface between convective and diffusive $\mathrm{CO}_{2}$ transport deeper into the lungs. ${ }^{10}$ 
Table 3. Dead Space

\begin{tabular}{|c|c|c|c|c|c|c|c|c|c|}
\hline \multirow{2}{*}{ Parameter } & \multirow{2}{*}{ Baseline } & \multicolumn{7}{|c|}{ PEEP } & \multirow{2}{*}{$P$} \\
\hline & & $0 \mathrm{~cm} \mathrm{H}_{2} \mathrm{O}$ & $5 \mathrm{~cm} \mathrm{H}_{2} \mathrm{O}$ & $10 \mathrm{~cm} \mathrm{H}_{2} \mathrm{O}$ & $15 \mathrm{~cm} \mathrm{H}_{2} \mathrm{O}$ & $20 \mathrm{~cm} \mathrm{H}_{2} \mathrm{O}$ & $25 \mathrm{~cm} \mathrm{H}_{2} \mathrm{O}$ & $30 \mathrm{~cm} \mathrm{H}_{2} \mathrm{O}$ & \\
\hline $\mathrm{V}_{\mathrm{D}_{\text {Bohr }}} / \mathrm{V}_{\mathrm{T}}$ & $0.52 \pm 0.05$ & $0.51 \pm 0.08$ & $0.52 \pm 0.09$ & $0.53 \pm 0.06$ & $0.55 \pm 0.05$ & $0.61 \pm 0.07$ & $0.65 \pm 0.08$ & $0.69 \pm 0.10$ & $<.001$ \\
\hline $\mathrm{V}_{\mathrm{D}_{\mathrm{aw}}} / \mathrm{V}_{\mathrm{T}}$ & $0.33 \pm 0.09$ & $0.32 \pm 0.08$ & $0.35 \pm 0.10$ & $0.33 \pm 0.10$ & $0.39 \pm 0.07$ & $0.44 \pm 0.10$ & $0.48 \pm 0.11$ & $0.53 \pm 0.13$ & $<.001$ \\
\hline $\mathrm{V}_{\mathrm{D}_{\text {alv }}} / \mathrm{V}_{\mathrm{T}_{\mathrm{alv}}}$ & $0.25 \pm 0.03$ & $0.27 \pm 0.05$ & $0.26 \pm 0.05$ & $0.25 \pm 0.02$ & $0.27 \pm 0.03$ & $0.30 \pm 0.03$ & $0.33 \pm 0.03$ & $0.35 \pm 0.06$ & $<.001$ \\
\hline $\mathrm{V}_{\mathrm{D}_{\mathrm{Eng}}} / \mathrm{V}_{\mathrm{T}}$ & $0.76 \pm 0.05$ & $0.86 \pm 0.02$ & $0.83 \pm 0.06$ & $0.80 \pm 0.06$ & $0.77 \pm 0.05$ & $0.80 \pm 0.03$ & $0.81 \pm 0.04$ & $0.84 \pm 0.04$ & $<.001$ \\
\hline $\mathrm{V}_{\mathrm{D}_{\text {alv }}} / \mathrm{V}_{\mathrm{T}_{\text {alv-Eng }}}$ & $0.64 \pm 0.13$ & $0.79 \pm 0.04$ & $0.75 \pm 0.11$ & $0.71 \pm 0.12$ & $0.61 \pm 0.11$ & $0.63 \pm 0.07$ & $0.64 \pm 0.07$ & $0.65 \pm 0.12$ & $<.001$ \\
\hline Expired $\mathrm{CO}_{2}$ per breath, $\mathrm{mL}$ & $6.1 \pm 3.2$ & $4.3 \pm 2.1$ & $5.1 \pm 3.1$ & $5.4 \pm 2.9$ & $5.7 \pm 3.0$ & $5.0 \pm 2.7$ & $4.6 \pm 2.5$ & $4.1 \pm 2.7$ & $<.001$ \\
\hline
\end{tabular}

Data are presented as mean $\pm \mathrm{SD}$. Analysis of variance $P$ values testing the influence of PEEP in each parameter are included in the last column.

$\mathrm{V}_{\mathrm{D}_{\text {Bohr }} / \mathrm{V}_{\mathrm{T}}}=$ Bohr's dead space

$\mathrm{V}_{\mathrm{D}} / \mathrm{V}_{\mathrm{T}}=$ airway dead-space-to-tidal-volume ratio

$\mathrm{V}_{\mathrm{D}_{\text {alv }}} / \mathrm{V}_{\mathrm{T}_{\text {alv }}}=$ alveolar dead-space-to-alveolar-tidal-volume ratio

$\mathrm{V}_{\mathrm{D}_{\text {Eng }}} / \mathrm{V}_{\mathrm{T}}=$ Enghoff index

$\mathrm{V}_{\mathrm{D}_{\text {alv }}} / \mathrm{V}_{\mathrm{T}_{\text {alv-Eng }}}=$ Enghoff's derived alveolar dead-space-to-alveolar-tidal-volume ratio
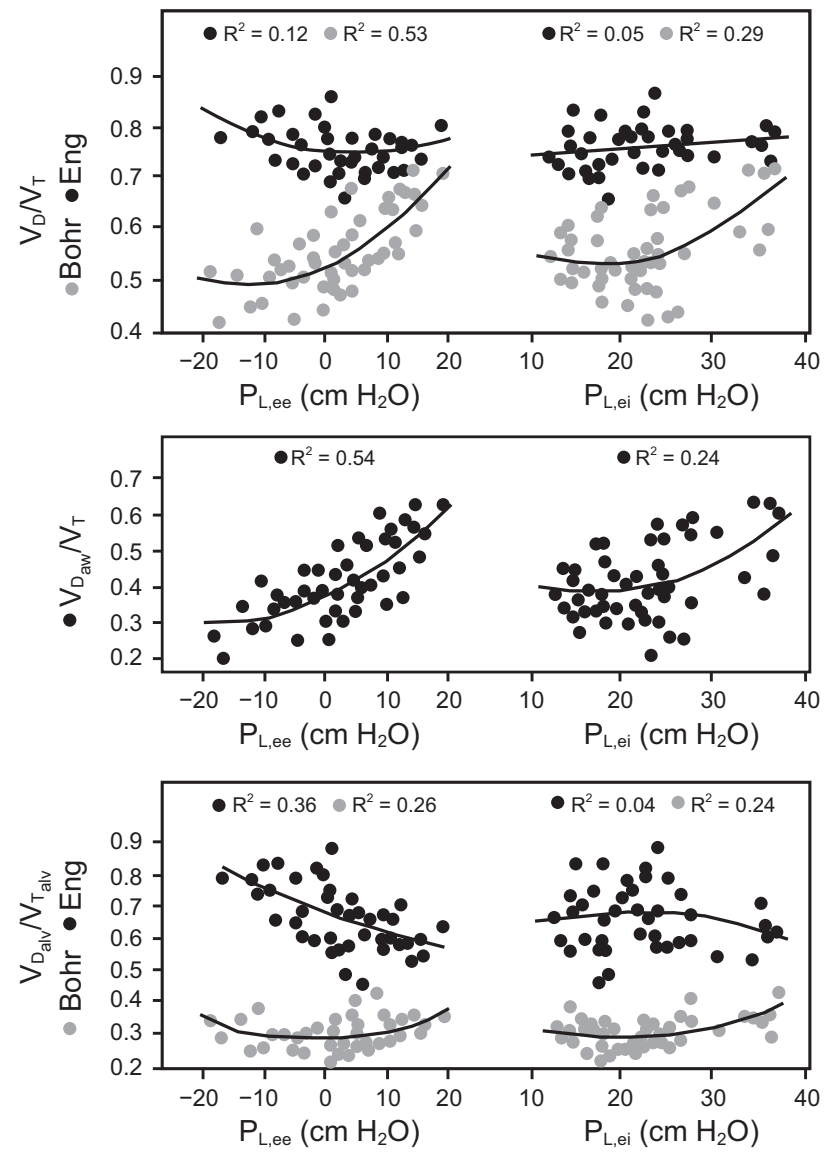

Fig. 4. The Bohr and Enghoff formulas as a function of endexpiratory, end-inspiratory, and transpulmonary pressures. Lines represent predicted values from quadratic regression models to assess non-linear relationships. Marginal $R^{2}$ values related to the fixed effect of the mixed models are also displayed. $\mathrm{P}_{\mathrm{L}, \text { ee }}$ and $\mathrm{P}_{\mathrm{L}, \mathrm{e}} / \mathrm{V}_{\mathrm{T}}=$ end-expiratory and end-inspiratory transpulmonary pressures, respectively; $\mathrm{V}_{\mathrm{D}_{\mathrm{aw}}} / \mathrm{V}_{\mathrm{T}}=$ airway dead space, $\mathrm{V}_{\mathrm{D}_{\text {alv }}} / \mathrm{V}_{\mathrm{T}_{\mathrm{alv}}}=$ alveolar dead space to alveolar tidal volume ratio.
The increase in airway dead space caused by PEEP has been observed in animal models and in subjects with ARDS. ${ }^{26-29}$ These studies showed $\mathrm{V}_{\mathrm{D}_{\text {aw }}} / \mathrm{V}_{\mathrm{T}}$ values much higher than the ones obtained in volunteers and in healthy mechanically ventilated subjects during anesthesia $\left(\mathrm{V}_{\mathrm{D}_{\text {aw }}} / \mathrm{V}_{\mathrm{T}} \sim 0.20\right) .{ }^{18}$ Our results correspond with those found in subjects with ARDS showing an increase in $\mathrm{V}_{\mathrm{D}_{\text {aw }}} / \mathrm{V}_{\mathrm{T}}$ almost proportional to PEEP (Fig. 2). When $\mathrm{V}_{\mathrm{D}_{\mathrm{aw}}} / \mathrm{V}_{\mathrm{T}}$ was presented as a function of end-expiratory $\mathrm{P}_{\mathrm{L}}$ or end-inspiratory $\mathrm{P}_{\mathrm{L}}$ using quadratic models, such a relationship fitted a curved shape function that described a nonlinear behavior (Fig. 4).

Reports of the effect of PEEP on $\mathrm{V}_{\mathrm{D}_{\text {alv }}}$ have been contradictory in previous publications. Beydon et $\mathrm{al}^{27}$ observed constant alveolar dead spaces in subjects with ARDS subjected to different levels of PEEP. Suter et al ${ }^{28}$ described nonlinear changes in $\mathrm{V}_{\mathrm{D}_{\text {alv }}}$ when PEEP was modified in mechanically ventilated subjects with respiratory failure. The authors reported that the "best" PEEP value was related to the lowest alveolar dead space and to the highest compliance and oxygen transport. It is, however, essential to note that these studies used the Enghoff formula, thereby including the effect of shunt. Thus, their conclusions are inappropriate with respect to real dead space. We illustrated the problem of including shunt in dead space estimations in an experimental model of ARDS, where $\mathrm{V}_{\mathrm{D}_{\text {alv }}}$ derived from the Enghoff equation increased proportional to the amount of shunt and nonaerated lung areas measured with computed tomography images at low levels of PEEP. ${ }^{26}$ In this study, our findings with the Enghoff approach produced results similar to those reported by Beydon et $\mathrm{al}^{27}$ and Suter et al. ${ }^{28} \mathrm{We}$ found a decrease in the Enghoff-derived $\mathrm{V}_{\mathrm{D}_{\text {alv }}} / \mathrm{V}_{\mathrm{T}_{\text {alv }}}$, which was associated to a increase in arterial oxygenation (Fig. 2). However, as opposed to the Bohr values, the Enghoff $\mathrm{V}_{\mathrm{D}_{\text {alv }}}$ ' $\mathrm{V}_{\mathrm{T}_{\text {alv }}}$ did not increase much with PEEP $>15 \mathrm{~cm} \mathrm{H}_{2} \mathrm{O}$, where 
lung recruitment and overdistention have mixed but opposite effects on this dead space value.

The Bohr formula, on the other hand, avoids any contamination by shunt because it derives its input values of $\mathrm{P}_{\overline{\mathrm{ECO}}_{2}}$ and alveolar $\mathrm{P}_{\mathrm{CO}_{2}}$ exclusively from gas samples measured within airways. ${ }^{8}, 9$ In contrast to the Enghoff parameters, the Bohr-derived alveolar dead space showed a curved shape when presented as function of end-expiratory $\mathrm{P}_{\mathrm{L}}$ and a linear behavior when related to endinspiratory $\mathrm{P}_{\mathrm{L}}$ (Fig. 4). Our $\mathrm{V}_{\mathrm{D}_{\text {alv }}} / \mathrm{V}_{\mathrm{T}_{\text {alv }}}$ values were 3 times higher than those observed in healthy subjects undergoing positive-pressure ventilation $\left(\mathrm{V}_{\mathrm{D}_{\text {alv }}} / \mathrm{V}_{\mathrm{T}_{\text {alv }}} \leq 0.10\right)$ and were slightly higher than those typically measured in patients with ARDS. ${ }^{18,29}$

At PEEP $\geq 15 \mathrm{~cm} \mathrm{H}_{2} \mathrm{O}$, the high $\mathrm{P}_{\text {plat }}$ and end-inspiratory $\mathrm{P}_{\mathrm{L}}$ were related to a high $\mathrm{V}_{\mathrm{D}_{\text {alv }}} / \mathrm{V}_{\mathrm{T}_{\mathrm{alv}}}$ (Figs. 2 and 3). Because hemodynamics and ventilation remained constant during the entire protocol, those variables are indicative of high lung stress, which increased the Bohr alveolar dead space component, thereby decreasing expired $\mathrm{CO}_{2}$ per breath.

At PEEP $<15 \mathrm{~cm} \mathrm{H}_{2} \mathrm{O}$, however, $\mathrm{P}_{\text {plat }}$ and end-inspiratory $\mathrm{P}_{\mathrm{L}}$ remained constant, though above the recommended safe values (Table 2, Fig. 3). Lung collapse at low PEEP values made lungs more heterogeneous, showing negative end-expiratory $\mathrm{P}_{\mathrm{L}}$ and increasing driving pressure, driving $\mathrm{P}_{\mathrm{L}}$, and lung elastance. These latter variables might reflect a cyclic strain as postulated by Amato et $\mathrm{al}^{30}$ and illustrated by Terragni et al ${ }^{31}$ using computed tomography images.

Retamal et $\mathrm{al}^{32}$ and Tsuchida et $\mathrm{al}^{33}$ reported in an experimental model that atelectasis acts as a stress concentrator, inducing local inflammation in ventilated lung areas. In another study, Retamal et al reported that the regional strain was spatially correlated with the inflammatory response within the ventilated areas. ${ }^{34}$ The presence of inflammation in ventilated lung zones due to tidal stretch of the baby lung has challenged our current understanding of the mechanisms of ventilator-induced lung injury. ${ }^{35,36}$

The increase in Bohr $\mathrm{V}_{\mathrm{D}_{\text {alv }}} / \mathrm{V}_{\mathrm{T}_{\text {alv }}}$ observed at low PEEP values could be a consequence of atelectasis as a stress concentrator, generating alveolar stretching and pulmonary capillary compression in the small functional lung. The decrease in expired $\mathrm{CO}_{2}$ per breath can be explained by this capillary compression (Table 3), as well as by the decrease in the area of gas exchange induced by atelectasis. This explanation is speculative because we measured neither strain nor capillary perfusion, which should be the focus of future studies.

\section{Clinical Implications}

The clinical implications of our findings point toward novel monitoring capabilities of volumetric capnography in relation to PEEP titration and adjustment of mechanical ventilation. At constant ventilation and stable hemody- namics, the level of PEEP had a significant influence on the efficiency of ventilation. The effect of PEEP on lung collapse and lung stress was well reflected by changes in the Bohr dead space, the Enghoff index, expired $\mathrm{CO}_{2}$ per breath, and lung mechanics.

Our results also highlighted the differences between the Bohr approach and the Enghoff approach. While the Bohr dead space represented the inefficiency of ventilation and provided information on the impact of positive pressure on the airways and alveoli, the Enghoff index was primarily affected by the shunt effect. Thus, the physiological implications of these approaches are different yet complementary and must be taken into account when interpreting such results in ventilated patients.

The Bohr dead spaces may help clinicians understand the functional impact of PEEP, not only on the elimination of $\mathrm{CO}_{2}$ and hypercapnia, but also on the stretch it exerts on the airways and alveoli. Because ARDS is a heterogeneous and complex lung condition, the response to PEEP or any other modification of the ventilator setting may be highly variable among patients. ${ }^{6,29}$ Thus, the Bohr dead space can help personalize lung-protective ventilation using volumetric capnography as a noninvasive, real-time, bedside monitoring method.

\section{Limitations}

The extreme range of PEEP values and $\mathrm{P}_{\text {plat }}$ investigated in our protocol was designed to test the ability of volumetric capnography to detect lung stress using the concept of dead space. Some of these PEEP and $\mathrm{P}_{\text {plat }}$ levels are clinically unacceptable, although they were necessary to answer our scientific questions. A factorial design with different tidal volumes would have added further important insights, but, in addition to being impractical to perform, such a design would also have changed dead space ratios. This added complexity might have rendered the interpretation of the results difficult, if not impossible.

The alveolar $\mathrm{P}_{\mathrm{CO}_{2}}$ differences observed in our study were higher than those observed in our previous publication in lung-lavaged pigs. ${ }^{37}$ These higher alveolar $\mathrm{P}_{\mathrm{CO}_{2}}$ values could be due to a more aggressive alveolar injury caused by the 2-hit model, changes in the distribution of pulmonary blood flow with exaggerated levels of PEEP, or even a potential systematic error in the NICO monitor measurements.

Pig's lungs and the 2-hit model are far removed from clinical findings in patients with ARDS, especially because the pig's airways are more distensible than those of humans and lavaged lungs are highly recruitable. Although our results show consistent and plausible patterns, the extrapolation of our findings to patients should be done with caution. 


\section{Conclusions}

In an animal model of ARDS, the Bohr dead space at high PEEP values were associated with an increase in both airway and alveolar dead-space components, as well as high airway and inspiratory transpulmonary pressures as indicators of excessive lung stress. At low PEEP values and in the presence of lung collapse, the Bohr alveolar dead space increased along with the driving pressures and lung elastance. This stretching of the alveolar compartment and the decrease in the elimination of $\mathrm{CO}_{2}$ at low levels of PEEP suggest an increase in inspiratory lung stress at small functional volumes (ie, baby lung). Contrary to the Bohr variables, the Enghoff indexes were highly influenced by atelectasis-induced shunt and, therefore, lost their ability to accurately detect alveolar lung stress.

\section{REFERENCES}

1. Fletcher R, Jonson B. Deadspace and the single breath test for carbon dioxide during anaesthesia and artificial ventilation. Effects of tidal volume and frequency of respiration. Br J Anaesth 1984;56(2):109-119.

2. Sinha P, Flower O, Soni N: Deadspace ventilation: a waste of breath! Intensive Care Med 2011;37(2):735-746.

3. Suarez-Sipmann F, Bohm SH, Tusman G. Volumetric capnography: the time has come. Curr Opin Crit Care 2014;20(3):333-339.

4. Bohr C. Über die Lungeatmung. Skand Arch Physiol 1891;2:236-238.

5. Enghoff H. Volumen inefficax. Bemerkungen zur Frage des schädlichen Raumes. Uppsala Läkareforen Forhandl 1938;44:191-218.

6. Rodriguez PO, Bonelli I, Setten M, Attie S, Madorno M, Maskin LP, Valentini R. Transpulmonary pressure and gas exchange during decremental peep titration in pulmonary ARDS patients. Respir Care 2013;58(5):754-763.

7. Fletcher R. Deadspace during anaesthesia. Acta Anaesthesiol Scand 1990;34(Suppl 94):46-50.

8. Tusman G, Suarez Sipmann F, Borges JB, Hedenstierna G, Bohm $\mathrm{SH}$. Validation of Bohr dead space measured by volumetric capnography. Intensive Care Med 2011;37(5):870-874.

9. Tusman G, Sipmann FS, Bohm SH. Rationale of dead space measurement by volumetric capnography. Anesth Analg 2012;114(4):866-874.

10. Schulz A, Schulz H, Heilmann P, Brand P, Heyder J. Pulmonary dead space and airways dimensions in dog at different levels of lung inflation. J Appl Physiol 1994;76(5):1896-1902.

11. Nieman GF, Paskanik AM, Bredenberg CE. Effect of positive endexpiratory pressure on alveolar capillary perfusion. J Thorac Cardiovasc Surg 1988;95(4):712-716.

12. Wagner P. Causes of high physiological dead space in critically ill patients. Crit Care 2008;12(1):148-149.

13. Milic-Emili J, Henderson JA, Dolovich MB, Trop D, Kaneko K. Regional distribution of inspired gas in the lung. J Appl Physiol 1966;21(3):749-759.

14. Chiumello D, Carlesso E, Cadringher P, Caironi P, Valenza F, Polli $\mathrm{F}$, et al. Lung stress and strain during mechanical ventilation for acute respiratory distress syndrome. Am J Respir Crit Care Med 2008;178(4):346-355.

15. Volpicelli G, Elbarbary M, Blaivas M, Lichtenstein DA, Mathis G, Kirkpatrick AW, et al. International evidence-based recommendations for point-of-care lung ultrasound. Intensive Care Med 2012; 38(4):577-591.
16. Talmor D, Sarge T, Malhotra A, O'Donnell CR, Ritz R, Lisbon A, et al. Mechanical ventilation guided by esophageal pressure in acute lung injury. N Engl J Med 2008;359(20):2095-2104.

17. Tusman G, Scandurra A, Bohm SH, Suarez Sipmann F, Clara F. Model fitting of volumetric capnograms improves calculations of airway dead space and slope of phase III. J Clin Monit Comput 2009;23(4):197-206.

18. Tusman G, Gogniat E, Bohm SH, Scandurra A, Suarez Sipmann F, Torroba A, et al. Reference values for volumetric capnography-derived non-invasive parameters in healthy individuals. J Clin Monit Comput 2013;27(3):281-288.

19. Fowler WS. Lung function studies II. The respiratory dead space. Am J Physiol 1948;154(3):405-416.

20. Tusman G, Bohm SH, Suarez Sipmann F, Scandurra A, Hedenstierna G. Lung recruitment and positive end-expiratory pressure have different effects on $\mathrm{CO} 2$ elimination in healthy and sick lungs. Anesth Analg 2010;111(4):968-977.

21. Nakagawa S, Schielzeth H. A general and simple method for obtaining R2 from generalized linear mixed-effects models. Methods Ecol Evol 2013;4(1):133-142.

22. Nunn JF, Hill DW. Respiratory dead space and arterial to endtidal CO2 difference in anesthetized man. J Appl Physiol 1960; 15(3):383-389.

23. Horsfield K, Cumming G. Functional consequences of airway morphology. J Appl Physiol 1968;24(3):384-390.

24. Gomez DM. A physico-mathematical study of lung function in normal subjects and in patients with obstructive pulmonary diseases. Med Thorac 1965;22(3):275-294.

25. Shepard RH, Campbell EJM, Martin HB, Enns T. Factors affecting the pulmonary dead space as determined by single breath analysis. J Appl Physiol 1957;11(2):241-244.

26. Tusman G, Suarez-Sipmann F, Bohm SH, Pech T, Reissmann H, Meschino G, et al. Monitoring dead space during recruitment and PEEP titration in an experimental model. Intensive Care Med 2006; 32(11):1863-1871.

27. Beydon L, Uttman L, Rawal R, Jonson B. Effects of positive endexpiratory pressure on dead space and its partitions in acute lung injury. Intensive Care Med 2002;28(9):1239-1245.

28. Suter PM, Fairley HB, Isenberg MD. Optimum end-expiratory airway pressure in patients with acute pulmonary failure. N Engl J Med 1975;292(6):284-289.

29. Gogniat E, Ducrey M, Dianti J, Madorno M, Roux N, Midley A, et al. Dead space analysis at different levels of positive end-expiratory pressure in acute respiratory distress syndrome. J Crit Care 2018; 45(3):231-238.

30. Amato MBP, Meade MO, Slutsky AS, Brochard L, Costa ELV, Schoenfeld DA, et al. Driving pressure and survival in the acute respiratory distress syndrome. N Engl J Med 2015;37(4):747-755.

31. Terragni PP, Rosboch G, Tealdi A, Corno E, Menaldo E, Davini O, et al. Tidal hyperinflation during low tidal volume ventilation in acute respiratory distress syndrome. Am J Respir Crit Care Med 2007;175(2):160-166.

32. Retamal J, Bergamini B, Carvalho AR, Bozza FA, Borzone G, Borges $\mathrm{JB}$, et al. Non-lobar atelectasis generates inflammation and structural alveolar injury in the surrounding healthy tissue during mechanical ventilation. Critical care 2014;18(8):505.

33. Tsuchida S, Engelberts D, Peltekova V, Hopkins N, Frndova H, Babyn $\mathrm{P}$, et al. Atelectasis causes alveolar injury in nonatelectatic lung regions. Am J Respir Crit Care Med 2006;174(3):279-289.

34. Retamal J, Hurtado D, Villarroel N, Bruhn A, Bugedo G, Amato MBP, et al. Does regional lung strain correlate with regional inflammation in acute respiratory distress síndrome during protective ventilation? An experimental porcine study. Crit Care Med 2018;46(6):e591-e599. 


\section{PEEP and Dead Space in a Porcine Model of ARDS}

35. Borges JB, Costa EL, Suarez-Sipmann F, Widstrom C, Larsson A, Amato MBP, Hedenstierna G. Early inflammation mainly affects normally and poorly aerated lung in experimental ventilator-induced lung injury. Crit Care Med 2014;42(4):e279-e287.

36. Bellani G, Messa C, Guerra L, Spagnolli E, Foti G, Patroniti N, et al. Lungs of patients with acute respiratory distress syndrome show diffuse inflammation in normally aerated regions: a $[18 \mathrm{~F}]-$
fluoro-2-deoxy-D-glucose PET/CT study. Crit Care Med 2009; 37(7):2216-2222.

37. Suarez Sipmann F, Santos A, Bohm SH, Borges JB, Hedenstierna G, Tusman G. Corrections of Enghoff's dead space formula for shunt effects still overestimate Bohr's dead space. Respir Physiol Neurobiol 2013;189(1):99-105.

This article is approved for Continuing Respiratory Care Education credit. For information and to obtain your CRCE

(free to AARC members) visit

www.rcjournal.com 